\title{
Temporal evolution of chromium leachability in compost, a case study in New-Caledonia
}

\author{
PERRINE KLEIN ${ }^{1,2,3}$, AUDREY LEOPOLD ${ }^{4}$, PEGGY \\ GUNKEL-GRILLON $^{2}$, HELENE KAPLAN ${ }^{3}$, FARID \\ JUILLOT $^{5}$ AND FREDERIC FEDER ${ }^{1,6}$ \\ ${ }^{1}$ Cirad \\ ${ }^{2}$ Université de la Nouvelle-Calédonie \\ ${ }^{3}$ Institut Agronomique néo-Calédonien \\ ${ }^{4}$ IAC - Institut Agronomique néo-Calédonien \\ ${ }^{5}$ ERL IRD 206, UMR 7590 CNRS-MNHN-Sorbonne Université \\ ${ }^{6}$ Université de Montpellier \\ Presenting Author: klein@iac.nc
}

Compost produced from municipal wastewater sludges and green wastes (MWSC) is a promising way for recycling wastewater sludges and for improving agricultural production. During the composting, organic matter is submitted to important changes leading to modifications on physico-chemical parameters. Little is known about the fate of chromium during composting process, while some changes in its speciation and leachability may be expected. This question is especially relevant In New-Caledonia, a French Archipelago, where the geochemical background highlights naturally high level of trace metal. Total chromium in soils can reach $30,000 \mathrm{mg} \mathrm{kg}^{-1}$ and MWSC can contain up to $1,200 \mathrm{mg} \mathrm{kg}^{-1}$, exceeding ten times the authorized contents in compost by the French regulation. In this work, we studied windrows MWSC composting at the initial $\left(t_{=0}\right)$ and final phases $\left(\mathrm{t}_{=6 \text { months }}\right)$ of composting. The total chromium content $\left(Q_{t o t}\right)$ was measured, and the leachability of chromium in compost was assessed with kinetic extractions using EDTA 0.05 $\mathrm{M}$ over $24 \mathrm{~h}$. Extraction curves were modeled as the sum of two first-order reactions to distinguish two mobile fractions from the total pool: one "labile" fraction $\left(Q_{1}\right)$, quickly extractable, with a rate constant $k_{l}$, and one "moderately labile" $\left(Q_{2}\right)$, less extractable with a rate constant $k_{2}$. The remaining fraction is the EDTA non-extractable pool. MWSC contained $327 \pm 5.9 \mathrm{mg} \mathrm{kg}$ dry mass $(\mathrm{DM})^{-1}$ and $426 \pm 8.1 \mathrm{mg} \mathrm{kg}_{\mathrm{DM}}{ }^{-1}$ of chromium at $\mathrm{t}_{=0}$ and $\mathrm{t}_{=6 \text { months }}$, respectively. For both maturity stages, the total mobilizable pool $\left(Q_{1}+Q_{2}\right)$ represented less than $3 \%$ of $Q_{\text {tot }}$. After 6 months of composting process, $Q_{\text {tot }}$ increased by 1.3 -fold due to loss of water and of volatile compounds. Nevertheless, the mobilizable pools varied differently. The $Q_{1}$ pool strongly increased with the composting process, being multiplied by 2.55 whereas the $Q_{2}$ pool decreased, i.e. it was divided by 1.33. These results indicated that the composting process increases the most labile fraction of chromium. The total mobilizable fraction of chromium represents a relative low fraction of $Q_{t o t}$. However, long term risks related to repeated compost application in agriculture must be considered as chromium could be potentially transferred to groundwater or cultivated plants, affecting agriculture production and human health. 